\title{
EDITORIAL A DVISORY BOARD
}

A. L. L. Baker, D.Sc.(Eng.), M.I.C.E., M.I.Struct.E.

Professor of Concrete Technology, University of London, Imperial College of Science and Technology

W. Fisher Cassie, Ph.D., M.S., F.R.S.E., M.I.C.E., M.I.Struct.E.

Professor of Civil Engineering, University of Durham, King's College, Newcastle upon Tyne

R. H. Evans, D.Sc., D. ès.Sc., Ph.D., M.I.C.E., M.I.Mech.E., M.I.Struct.E.

Professor of Civil Engineering, University of Leeds

T. W. Parker, M.Sc., Ph.D., F.R.I.C.

Deputy Director of Building Research, Department of Scientific and Industrial Research

A. D. Ross, B.Sc., Ph.D., F.R.S.E., M.I.C.E.

Professor of Civil Engineering, University of London, King's College

SECRETARY TO THE BOARD AND EDITOR

Ralph P. Andrew, M.A., Ph.D.

Published by the Cement and Concrete Association, 52 Grosvenor Gardens, London, SW1 : Belgravia 6661

\section{Editorial comment}

IT IS PERHAPS UNUSUAL, in an editorial comment, to comment on matters editorial; editors do not usually complain -at least, not in public -of the trials and tribulations of their duties. Nevertheless, with a little foresight and an occasional discussion with the editor, authors could often simplify considerably the job of getting their papers into print, and could often avoid completely the irritation at having their manuscripts altered.

The first-but not the only--hurdle to be overcome by intending authors is that of having their papers accepted for publication, and yet a surprising proportion of the papers submitted for consideration do not appear to have had much attention paid to their presentation. There are always more papers submitted for publication than can be accepted, and if two papers are of equal scientific value, the one that is better presented and easier to read will naturally be preferred to the other. If a manuscript is badly typed, if any mathematical working is badly laid out, if the illustrations are not clear, then any referee is biased against a paper from the start, whatever its scientific value. If the paper is badly written, or if it is much longer than it need be, he will resent the time he must spend in reading right through it. $\mathrm{He}$ is irritated by the bad presentation, and will not feel kindly disposed towards the paper. Thus the author has to overcome this unreceptive mood which he has provoked in the referee, and has jeopardized his chances of having the paper published. If-as it seems reasonable to suppose-an author is anxious to have his paper published, it is in his own interests to make it easy to read; if the referee is put into a receptive mood as soon as he picks up the paper, then the author has considerably improved his chances. It is of little use thinking that the paper will be all right once it is printed: it may never be printed.

Once a paper has been accepted, the editor appears on 
the scene. His concern is not so much the technical merit of the papers but their conversion from manuscript to print, and although he himself can perhaps understand the author's mathematical workings, he has to instruct the printer to whom the whole paper probably means nothing whatsoever. Every letter, symbol and sign, and every space, on every page of this Magazine, represents a separate bit of metal with the printer, and although the setting in type of ordinary text is fully mechanized, mathematical equations must nearly all be put together by hand. When it is realized that a single-line equation in this Magazine may easily consist of 60 separate bits of metalall of which are "inside out" to the compositor-it will be seen that the printer's job is difficult enough without any confusion the author may cause by using both omega $(\omega)$ and double-u $(w)$ in the same manuscript. The author can do much to help, particularly in mathematical texts. Simple indices and suffixes present no problem, but indices to indices and suffixes to suffixes, although simple enough to write by hand, are extremely difficult to set in type. Modifications to symbols, such as in $f_{t}$, are quite simple, but modifying signs placed above or below a symbol (e.g. $\dot{x}, \bar{x}$ ) can be an infuriating nuisance unless the printer happens to have a range of letters of the right size modified in this way. If, therefore, modified symbols are required, those should be chosen which will cause least difficulty to the printer.

Diagrams are another frequent source of difficulty. When preparing them in the first place, the author should remember that they will have to be reduced to go on the page, and should avoid cluttering them up with a whole mass of explanation. In particular, he should avoid giving scales in the form " 1 in. $=1 \mathrm{ft} "$, which it is very unlikely will remain true. In the Magazine of Concrete Research it is the practice to set in type all lettering required on diagrams, so it is better to leave the tracings unlettered. Any lettering required can be indicated on prints of the tracings, and as long as this is done clearly, no difficulty will arise.

Whenever possible, however, it is advisable for a prospective author to have a word with the editor before starting to write a paper. A few minutes' discussion in the first place may well save much trouble later, for the printer, the editor, and, indeed, for the author himself. 